\title{
DEVELOPMENT AND EVALUATION OF SUSTAIN RELEASE MICROPARTICLES OF METOPROLOL SUCCINATE
}

\author{
SUMA OOMMEN SEN ${ }^{*}$, PRITESH DEVBHUTI ${ }^{2}$, KALYAN KUMAR SEN ${ }^{1}$, AMITAVA GHOSH ${ }^{3}$
}

${ }^{1}$ Gupta College of Technological Sciences, Ashram More, G.T. Road, Asansol, West Bengal, India, 713301, ${ }^{2}$ NSHM College of Pharmaceutical Technology, 124, B L Saha Road, Kolkata 700053, India, ${ }^{3}$ Bengal College of Pharmaceutical Sciences and Research, B.R.B.Sarani, Bidhannagar, Durgapur, West Bengal, India

Email: suma_kpa@yahoo.co.in

Received: 26 Dec 2018, Revised and Accepted: 04 Jul 2019

\begin{abstract}
Objective: In this study, xanthan gum was oxidized by sodium periodate to form xanthan dialdehyde. This oxidized gum was used as crosslinking agent as an alternative to somewhat toxic glutaraldehyde, the basis of which is the reaction between the Schiff reagent and the aldehydes formed by periodate oxidation.

Methods: Formation of aldehyde groups were confirmed by Fourier Transform Infrared Spectroscopy (FTIR). Microparticles of metoprolol succinate were fabricated using crosslinking of a chitosan/gelatin mix system by dialdehyde Xanthan gum. The properties of the developed microparticles were investigated with swelling equilibrium studies, differential scanning calorimeter (DSC), in vitro drug release studies and scanning electron microscopy (SEM).

Results: The in vitro drug release from these microparticles was affected by total polymer amount, oxidation reaction time and chitosan to gelatin ratio. The cumulative percent release of metoprolol succinate was observed within the range of 46 to $95 \%$ at $8 \mathrm{~h}$ from different formulations studied. The factors identified as significant to produce any impact on drug loading as well as drug release were both the polymer and inter actions of polymer and Xanthan gum dialdehyde.
\end{abstract}

Conclusion: The release mechanism followed the super case II model kinetics.

Keywords: Xanthan gum Dialdehyde, Periodate oxidation, Schiff's reagent, Chitosan, Gelatin

(C) 2019 The Authors. Published by Innovare Academic Sciences Pvt Ltd. This is an open access article under the CC BY license (http://creativecommons.org/licenses/by/4.0/] DOI: http://dx.doi.org/10.22159/ijap.2019v11i5.31664

\section{INTRODUCTION}

Scientists throughout the world are engaged in developing biopolymer based biodegradable drug delivery system for various purposes like targeted drug delivery system, controlled release drug delivery systems, chronotherapeutic drug delivery systems etc due to non toxic nature of biomaterials, their biocompatibility, low cost and easily modifiable chemically to develop desired polymer $[1,2]$. Gelatin is widely studied for drug delivery applications because of its low cost, renewability and biodegradability. But in aqueous environments gelatin is rapidly solubilized to produce fast drug release and low mechanical stability [3]. To overcome this disadvantage several researchers cross linked gelatin molecules by treating with di-or polyaldehydes to develop less or non-soluble products which can prevent the release of the drug from the matrices [4]. However, the presence of these residual cross-linking agents may cause toxic side effects. So the uses of 'natural' cross-linking agents, such as periodate oxidized gums [5] have been studied for the formation of gelatin devices for several purposes whose aldehyde groups can crosslink with 3-amino groups of lysine or hydroxylysine side groups of protein by Schiff's base formation [6]. On the other hand chitosan [Poly $(1,4-\beta$ D-glucopyranosamine)], N-deacetylated polysaccharide from chitin, also has an amino group in its monomer unit. Cross-linked Chitosan micro or nanoparticles are widely studied for targeted or controlled drug delivery [7]. It can also react with oxidized gum by Schiff's base formation. It was postulated that dialdehyde polysaccharides. In the presence of sodium periodate, the oxidation of xanthan gum is characterized by the specific cleavage of C2-C3 bond of residues, resulting in the formation of aldehyde groups.

So we have hypothesized that when a mixture of gelatin and chitosan would react with the xanthan dialdehyde that will result crosslinking of both the polymer chain. This will cause entanglement of polymer chains to result Interpenetrating Polymer Network (IPN), which is a blend of two or more polymers in a network with at least one of the systems synthesized in the presence of another [8]. This produces a formation of physically cross-linked network when polymer chains of the second system are entangled with or penetrate the network formed by the first polymer. Each individual network retains its individual properties so synergistic improvements in properties like strength or toughness can be seen [9]. Literature survey suggested that IPN based microparticles of metoprolol succinate using non-toxic xanthan gum dialdehyde as crosslinker for both chitosan and gelatin was not studied till date. This is the novelty of the formulation. So, the main objective of this study was to develop microparticles of metoprolol succinate using a chitosan/gelatin IPN material by crosslinking with dialdehyde Xanthan. The properties of the microparticles were investigated with Fourier Transform Infrared Spectroscopy (FTIR), equilibrium swelling studies, differential scanning calorimeter (DSC), X- ray diffraction (XRD) analysis, in vitro drug release studies, and scanning electron microscopy (SEM).

\section{MATERIALS AND METHODS}

\section{Materials}

Metoprolol succinate was generously gifted by IPCA Laboratories Limited, Mumbai. Chitosan was purchased from Everest Biotech, Bangalore. The degree of deacetylation is $>85 \%$. Xanthan gum, pentasodium tripolyphosphate (TPP), acetic acid, isopropyl alcohol, propylene glycol and gelatin were purchased from Hi media. Sodium periodate was purchased from Loba Chemicals. All other reagents used are of analytical grade. In all purposes all glass double distilled water was used.

\section{Preparation of oxidized xanthan gum}

Oxidized xanthan gum was prepared as reported in the literature with little modifications [10]. About $1.0 \mathrm{~g}$ xanthan gum was dissolved in $20 \mathrm{ml}$ distilled water. Then, $10 \mathrm{ml}$ sodium periodate solution of $0.1 \mathrm{~g} / \mathrm{ml}$ was added to the xanthan gum solution under stirring. The $\mathrm{pH}$ was adjusted to 5.0 with $1 \mathrm{M}$ sulfuric acid solution. After that the mixture was kept in the dark at $40{ }^{\circ} \mathrm{C}$ for $6 \mathrm{~h}$ and $24 \mathrm{~h}$ with stirring, the prepared oxidized xanthan gum was precipitated 
by pouring the solution into a large amount of ethanol. The precipitate was then recovered and repeatedly washed with distilled water and ethanol until all iodic compounds were removed. The product was dried at $50{ }^{\circ} \mathrm{C}$ to constant weight for the subsequent use. The obtained oxidized xanthan gum was named XDA1 and XDA2 for $6 \mathrm{~h}$ and $24 \mathrm{~h}$ incubation respectively.

\section{Determination of aldehyde content}

The degree of oxidation was evaluated by titration method using hydroxylamine hydrochloride as elaborated in literature [11]. In brief, an excess of hydroxylamine hydrochloride was reacted with oxidized xanthan gum that formed hydrochloric acid. It was then titrated with $\mathrm{NaOH}$ and aldehyde content in oxidized xanthan gum was calculated from it. The same concentration of xanthan gum solution at $\mathrm{pH} 5$ was used as a blank and its consumption of the alkali solution in liter was recorded.

The degree of oxidation was calculated according to the following equation where $\mathrm{V}_{\mathrm{a}}$ is the consumed volume of $\mathrm{NaOH}$ solution $(0.1 \mathrm{M})$ at the equivalence point, $\mathrm{n}$ is the possible number of aldehyde groups, $\mathrm{m}$ is the dry weight of oxidized $\mathrm{XG}$ and $934 \mathrm{~g} / \mathrm{mol}$ is the molecular weight of the repeating unit of XG. In the case of xanthan gum, eight aldehyde groups can be formed per repeating unit by the cleavage of the $\mathrm{C}-\mathrm{C}$ bond between adjacent- $\mathrm{CHOH}$ groups.

$$
\text { Degree of oxidation } \%=\frac{\mathrm{V}_{\mathrm{a}} \times 0.1 \times 100}{\mathrm{n} \times \mathrm{m} \times 934}
$$

\section{Preparation of microparticles of chitosan gelatin cross-linked} with xanthan dialdehyde.

Gelatin solution $(10 \%, \mathrm{w} / \mathrm{v})$ was prepared by soaking gelatin powder in distilled water for $30 \mathrm{~min}$ and then heated at $60^{\circ} \mathrm{C}$ for $30 \mathrm{~min}$ under continuous stirring. Chitosan $1 \% \mathrm{w} / \mathrm{v}$ solution was prepared in dilute acetic acid solution. Both the Chitosan and gelatin solutions were mixed and the $\mathrm{pH}$ was raised to 5 . Oxidized xanthan gum solution $(10 \%, \mathrm{w} / \mathrm{v})$ was prepared in borax solution and $\mathrm{pH}$ was adjusted to 9 . The resulting Chitosan and gelatin mixture was added dropwise with the help of a syringe to the oxidized xanthan gum solution at $40{ }^{\circ} \mathrm{C}$ with stirring for $2 \mathrm{~h}$ to obtain microparticles. Then this microparticles were again incubated in $1 \% \mathrm{w} / \mathrm{v}$ TPP solution for $2 \mathrm{~h}$.

\section{Experimental design}

A full factorial $2^{4}$-design was employed to study the effect of independent variables. Optimization of the formulation development process was performed using statistical experimental design with a software DESIGN EXPERT ${ }^{\circledR}$ version 7.0.2.8 (Stat-Ease Inc., Minneapolis, USA)[12]. Response surface diagrams were used to show the factor interaction between the independent considered variables. Selected independent variables studied were the amount of total polymer(X1), $\%$ of $2^{\text {nd }}$ polymer i.e. gelatin(X2), Oxidation reaction time (X3) and amount of drug (X4). Two factorial levels coded for low, and high settings $f(1$ and +1 , respectively) were considered for four independent variables. The selected dependent variables investigated were the Entrapment Efficiency value (Y1), and cumulative percent release (CPR) at $8 \mathrm{~h}$ (Y2) Formulations F1-F16 were prepared by varying the levels of the independent variables as required by the experimental design and factors levels along with the results of dependent variables were mentioned in table 1 .

\section{Swelling study}

The progress of water sorption in the microsphere was determined by the help of swelling study. The swelling characteristics of microsphere were determined by immersing dried microsphere in different buffer solution until equilibrium is achieved. A $10 \mathrm{mg}$ of microsphere was taken in a beaker containing $10 \mathrm{ml}$ different solutions [pH1.2 buffer solution and phosphate buffer solution of $\mathrm{pH}$ 6.8] for $8 \mathrm{~h}$ at $37^{\circ} \mathrm{C}$. At specific time intervals, the samples were removed from the swelling medium and were blotted with a piece of paper to absorb excess water on the surfaces. The swelling ratios (Qs) of test samples were calculated from the following expression:

$$
\mathrm{Q}_{\mathrm{s}}=\frac{(W s-W d)}{W d} \times 100
$$

Where $W_{s}$ is the weight of the swollen test sample and $W_{d}$ is the weight of the dried test sample.

\section{In vitro release study}

In vitro release study was carried out by using a type 1 dissolution test apparatus. In brief, $20 \mathrm{mg}$ of microsphere was accurately weighed and placed in $500 \mathrm{ml}$ phosphate buffer of $\mathrm{pH} 6.8$ [SIF) in the dissolution flask at a temperature of $37^{\circ} \mathrm{C} \pm 0.5^{\circ} \mathrm{C}$ with $50 \mathrm{rpm}$ stirring speed of the paddle. At a particular time interval $5 \mathrm{ml}$ sample was withdrawn and replenish with fresh buffer solution. The aliquots samples were analyzed using double beam spectrophotometer at $276 \mathrm{~nm}$.

\section{Kinetic analysis of release data of tablets}

Different model equations were used to analyze the in vitro dissolution data of metoprolol release from the microparticles and to study the release mechanism. It has been observed that the release rates follow zero-order, Weibull and the Korsmeyer and Peppas equation. The software KinetDS3.0 was used to study the model fitting. The $\mathrm{n}$ value of the Korsmeyer and Peppas equation is an exponent used to characterize the transport mechanism. Here we obtained $\mathrm{n}$ value $>0.89$ that suggests for Super Case II transport. Case II relaxation release is the drug transport mechanism associated with stresses and state-transition in hydrophilic glassy polymers, which swell in water or biological fluids. Case II generally refers to erosion of polymeric chain and anomalous transport (non-fickian) refers to a combination of both diffusion and erosion controlled drug release.

\section{RESULTS AND DISCUSSION}

\section{Preparation of microsphere}

In present investigation, native xanthan gum was oxidized with sodium periodate at room temperature. It had been assumed that hydroxyl group on carbon 2 and 3 of the repetitive unit were oxidized by sodium periodate which caused rupturing of carboncarbon bond to the formation of two aldehyde group in each oxidized monomeric unit. This oxidized xanthan was subsequently cross-linked with chitosan and gelatin to form drug loaded microsphere by ionotropic gelation method in completely aqueous environment. In this present study borax is also used. Gelatin increased the rigidity of the structure and also increased the swelling property, drug entrapment efficiency and drug release rate. As it is Schiff base reaction borax is used for higher $\mathrm{pH}$ reaction. Borax also increases the spherical shape of the microsphere. A full factorial $2^{4}$-design was employed to develop optimized formulatin. The effects of different variables are recorded in table 1.

\section{FT-IR analysis}

The FT-IR spectra of xanthan gum and xanthan gum dialdehyde were compared and it was represented in fig. 1a and b. FT-IR spectrum of xanthan gum showed absorption band at $1604.77 \mathrm{~cm}^{-1}$ and $1411.89 \mathrm{~cm}^{-1}$ was assigned to asymmetric stretching and symmetric stretching peak of the carboxylate salt group. The presence of aldehydes group was confirmed by $\mathrm{C}=0$ stretching band at $1724.30 \mathrm{~cm}^{-1}$.

\section{Drug entrapment efficiency}

The drug percent entrapment efficacy of nanoparticles was achieved between $94.36 \%-52.74 \%$. Drug entrapment was found more in the formulation having greater polymer concentration and found less in the formulation having less polymer concentration. This is due to the increased availability of the polymer for encapsulating the drug. The presence of gelatin also increases drug entrapment efficiency. Response surface diagram (fig. 3) clearly indicates that total polymer and presence of gelatin influence drug entrapment efficiency.

\section{Experimental design}

The present study consisted of a two-level full-factorial Design for four factors $\left(2^{4}\right)$ for experimentation. Optimization of the formulation development process was performed using statistical experimental design with a software DESIGN EXPERT ${ }^{\circledR}$ version 7.0.2.8 (Stat-Ease Inc., Minneapolis, USA). Response surface diagrams (fig. 3) were used to show the factor interaction between the independent considered variables. Two factorial levels coded for low, and high settings ( -1 and +1 , respectively) were considered for 
four independent variables. The selected dependent variables investigated were the Drug Entrapment Efficicency value (Y1), and $\mathrm{CPR}$ at $8 \mathrm{~h}$ (Y2). A total of 16 experimental runs were required for analyzing the interaction of each level on formulation characters and to optimize. Table 1 shows the factors were chosen and different factor level settings. The response in each trial was measured by carrying out a multiple factorial regression analysis using the quadratic model:

Table 1: $2^{4}$ Full factorial design for different formulations of metoprolol succinate microparticles with dependant variables

\begin{tabular}{|c|c|c|c|c|c|c|}
\hline $\begin{array}{l}\text { Formulation } \\
\text { No. } \\
\end{array}$ & $\begin{array}{l}\text { Total Polymer } \\
\text { (mg) (X1) }\end{array}$ & $\begin{array}{l}\text { Gelatin } \\
\text { (\% of X1) (X2) }\end{array}$ & $\begin{array}{l}\text { Oxidation reaction } \\
\text { time (h) (X3) }\end{array}$ & $\begin{array}{l}\text { Drug } \\
\text { (mg) (X4) }\end{array}$ & $\begin{array}{l}\text { DEE\# } \\
\text { (\%) (Y1) }\end{array}$ & $\begin{array}{l}\text { CPR* } \\
(\%)(Y 2) \\
\end{array}$ \\
\hline F1 & 200 & 30 & 24 & 100 & $94.94 \pm 2.43$ & $81.82 \pm 2.12$ \\
\hline $\mathrm{F} 2$ & 100 & 30 & 24 & 100 & $59.89 \pm 3.71$ & $94.76 \pm 2.45$ \\
\hline F3 & 200 & 0 & 24 & 100 & $79.43 \pm 1.76$ & $76.34 \pm 2.18$ \\
\hline $\mathrm{F} 4$ & 100 & 0 & 24 & 100 & $56.51 \pm 2.92$ & $83.17 \pm 1.89$ \\
\hline F5 & 200 & 30 & 6 & 100 & $92.36 \pm 1.34$ & $73.44 \pm 1.57$ \\
\hline F6 & 100 & 30 & 6 & 100 & $62.00 \pm 2.03$ & $92.00 \pm 1.05$ \\
\hline F7 & 200 & 0 & 6 & 100 & $80.42 \pm 1.89$ & $68.23 \pm 1.87$ \\
\hline F8 & 100 & 0 & 6 & 100 & $59.11 \pm 1.46$ & $92.23 \pm 2.07$ \\
\hline F9 & 200 & 30 & 24 & 50 & $87.67 \pm 2.12$ & $46.61 \pm 1.83$ \\
\hline F10 & 100 & 30 & 24 & 50 & $67.32 \pm 1.85$ & $90.65 \pm 2.09$ \\
\hline F11 & 200 & 0 & 24 & 50 & $80.22 \pm 3.12$ & $62.41 \pm 0.64$ \\
\hline F12 & 100 & 0 & 24 & 50 & $52.63 \pm 1.09$ & $83.71 \pm 1.58$ \\
\hline F13 & 200 & 30 & 6 & 50 & $90.7 \pm 1.67$ & $76.56 \pm 1.58$ \\
\hline F14 & 100 & 30 & 6 & 50 & $64.42 \pm 2.23$ & $95.22 \pm 2.45$ \\
\hline F15 & 200 & 0 & 6 & 50 & $81.64 \pm 2.91$ & $72.41 \pm 1.73$ \\
\hline F16 & 100 & 0 & 6 & 50 & $58.16 \pm 0.78$ & $86.32 \pm 2.32$ \\
\hline
\end{tabular}

$\mathrm{DEE}=$ Drug Entrapment Efficiency, $\mathrm{CPR}=$ Cumulative Percent Release, all values are expressed as mean $\pm \mathrm{SD}, \mathrm{\#}=3$ * $\mathrm{n}=3$

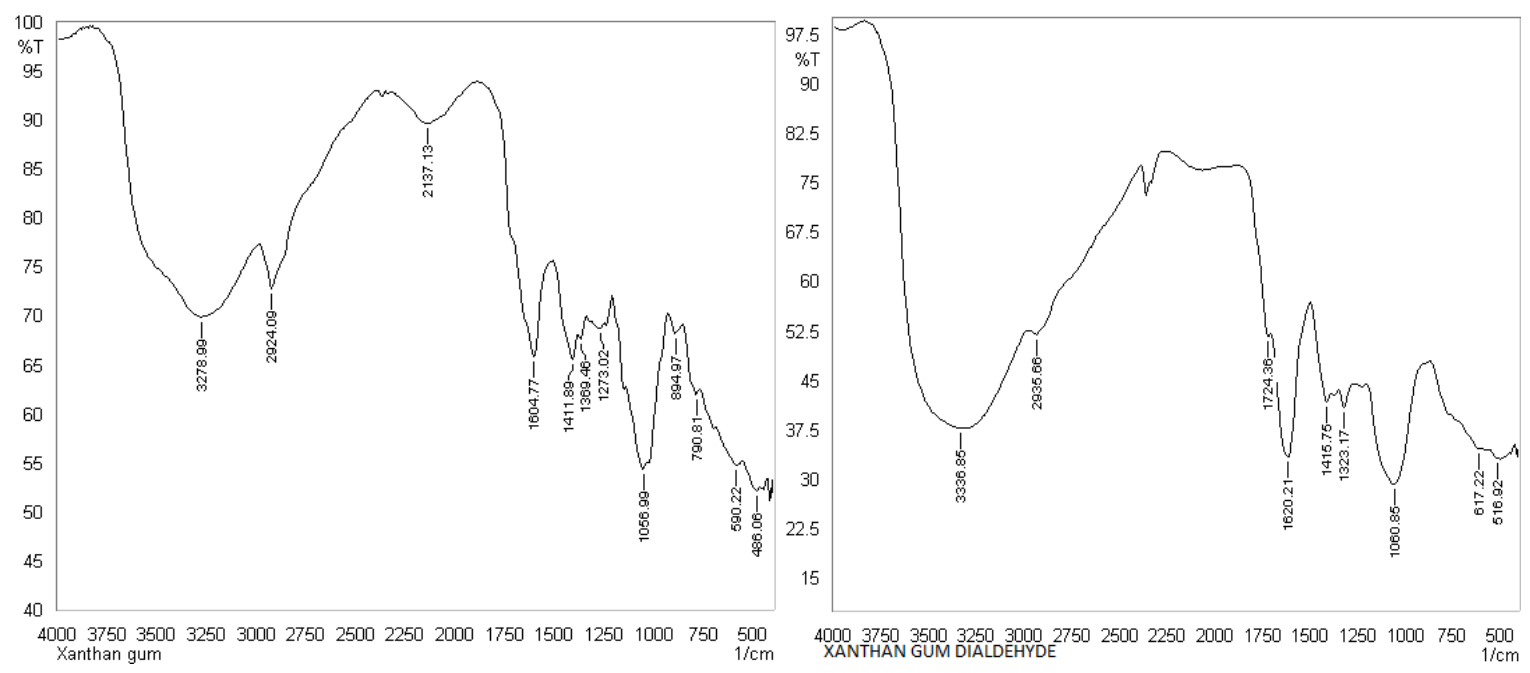

a.

b.

Fig. 1: FTIR spectra of xanthan gum (a) and its dialdehyde (b)

Table 2: ANOVA study result

A. ANOVA study result for a selected factorial model for the response Y2(CPR at $8 \mathrm{~h}$ )

\begin{tabular}{|c|c|c|c|c|c|}
\hline Source & Sum of Squares & df & Mean square & F-value & p-value \\
\hline Model & 2676.31 & 11 & 243.30 & 29.43 & significant \\
\hline X1-Total amt polymer & 1683.05 & 1 & 1683.05 & 203.56 & 0.0001 \\
\hline X2-amt Gelatin & 56.63 & 1 & 56.63 & 6.85 & 0.0590 \\
\hline X3-oxidation reaction time & 68.39 & 1 & 68.39 & 8.27 & 0.0452 \\
\hline X4-drug amt & 122.32 & 1 & 122.32 & 14.79 & 0.0184 \\
\hline $\mathrm{X} 1 * \mathrm{X} 2$ & 64.08 & 1 & 64.08 & 7.75 & 0.0496 \\
\hline $\mathrm{X} 1 * \mathrm{X} 4$ & 97.22 & 1 & 97.22 & 11.76 & 0.0266 \\
\hline $\mathrm{X} 3 * \mathrm{X} 4$ & 178.62 & 1 & 178.62 & 21.60 & 0.0097 \\
\hline $\mathrm{X} 1 * \mathrm{X} 2 * \mathrm{X} 3$ & 69.72 & 1 & 69.72 & 8.43 & 0.0439 \\
\hline $\mathrm{X} 1 * \mathrm{X} 2 * \mathrm{X} 4$ & 58.83 & 1 & 58.83 & 7.12 & 0.0560 \\
\hline $\mathrm{X} 1 * \mathrm{X} 3 * \mathrm{X} 4$ & 220.67 & 1 & 220.67 & 26.69 & 0.0067 \\
\hline $\mathrm{X} 2 * \mathrm{X} 3 * \mathrm{X} 4$ & 56.78 & 1 & 56.78 & 6.87 & 0.0588 \\
\hline Residual & 33.07 & 4 & 8.27 & & \\
\hline Cor Total & 2709.39 & 15 & & & \\
\hline
\end{tabular}


B. ANOVA study result for a selected factorial model for the response Y2(CPR at $8 \mathrm{~h}$ )

\begin{tabular}{|c|c|c|c|c|c|}
\hline Source & Sum of squares & df & Mean square & F-value & p-value \\
\hline Model & 3103.34 & 13 & 238.72 & 146.76 & significant \\
\hline A-Total amt polymer & 2686.87 & 1 & 2686.87 & 1651.82 & 0.0006 \\
\hline B-amt Gelatin & 316.66 & 1 & 316.66 & 194.68 & 0.0051 \\
\hline C-cross linking time & 6.50 & 1 & 6.50 & 4.00 & 0.1836 \\
\hline $\mathrm{AB}$ & 17.51 & 1 & 17.51 & 10.77 & 0.0817 \\
\hline $\mathrm{AC}$ & 1.25 & 1 & 1.25 & 0.7712 & 0.4725 \\
\hline $\mathrm{AD}$ & 8.91 & 1 & 8.91 & 5.48 & 0.1441 \\
\hline $\mathrm{BC}$ & 7.40 & 1 & 7.40 & 4.55 & 0.1666 \\
\hline $\mathrm{BD}$ & 0.8742 & 1 & 0.8742 & 0.5375 & 0.5398 \\
\hline $\mathrm{CD}$ & 0.9801 & 1 & 0.9801 & 0.6025 & 0.5188 \\
\hline $\mathrm{ABD}$ & 41.02 & 1 & 41.02 & 25.22 & 0.0374 \\
\hline ACD & 4.12 & 1 & 4.12 & 2.53 & 0.2524 \\
\hline BCD & 0.4761 & 1 & 0.4761 & 0.2927 & 0.6427 \\
\hline $\mathrm{ABCD}$ & 10.76 & 1 & 10.76 & 6.61 & 0.1237 \\
\hline Residual & 3.25 & 2 & 1.63 & & \\
\hline Cor Total & 3106.60 & 15 & & & \\
\hline
\end{tabular}

Analysis of variance (ANOVA) was applied for the estimation of the significance of the model. Using a $5 \%$ significance level, a model was considered significant if the $\mathrm{p}<0.05$. It was found that after removal of some insignificant factors for responses both Y1 and Y2 the linear contribution model were significant $(\mathrm{p}<0.001)$. Table 2 shows the factor effects of the quadratic model and associated $\mathrm{p}$ values for all five responses. The Model F-value of 29.43 implies the model is significant. There is only a $0.77 \%$ chance that a "Model F-value" this large could occur due to noise. Values of "Prob>F" less than 0.0500 indicate model terms are significant. In this case $\mathrm{X} 1, \mathrm{X} 3, \mathrm{X} 4, \mathrm{X} 1 * \mathrm{X} 2$, $\mathrm{X} 1 * \mathrm{X} 4, \mathrm{X} 3 * \mathrm{X} 4, \mathrm{X} 1 * \mathrm{X} 2 * \mathrm{X} 3$ and $\mathrm{X} 1 * \mathrm{X} 3 * \mathrm{X} 4$ are significant model terms.

Fig. 2 shows the pareto chart of t-value of effect vs rank for the factor $\mathrm{Y} 2$. It also indicates that $\mathrm{X} 1, \mathrm{X} 3, \mathrm{X} 4, \mathrm{X} 1 * \mathrm{X} 2, \mathrm{X} 1 * \mathrm{X} 4, \mathrm{X} 3 * \mathrm{X} 4$, $\mathrm{X} 1 * \mathrm{X} 2 * \mathrm{X} 3$ and $\mathrm{X} 1 * \mathrm{X} 3 * \mathrm{X} 4$ are significant model terms because the $\mathrm{t}=\mathrm{value}$ of these single factors and interaction effects are lying between Bonferroni Limit 6.25407 t-Value Limit 2.77645.
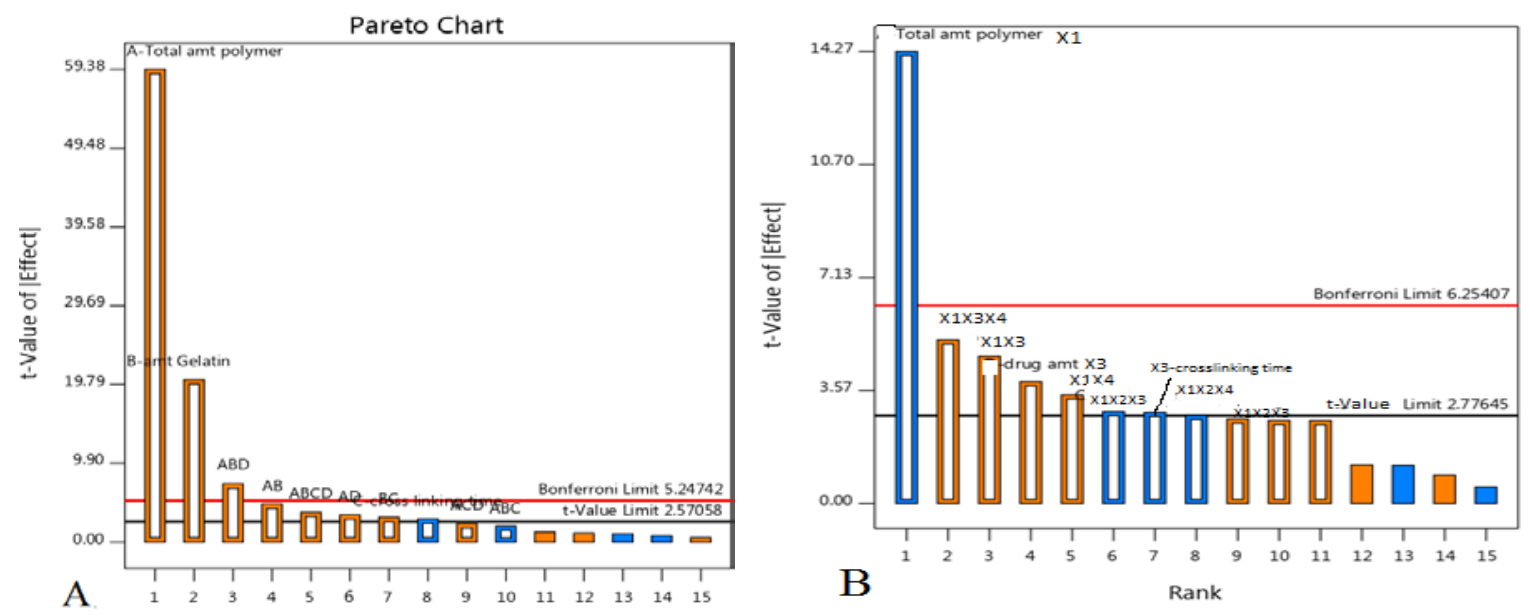

Fig. 2: Pareo chart of t-value of effect vs rank for the factor Y1(A) and Y2 (B)

\section{Final equation in terms of coded factors}

\section{For response CPR at $8 \mathrm{H}$}

$\mathrm{CPR}$ at $8 \mathrm{~h}(\mathrm{Y} 2)=+79.98+10.26 * \mathrm{X} 1+1.88 * \mathrm{X} 2-2.07 * \mathrm{X} 3+2.88 * \mathrm{X} 4-$ $2.0 * \mathrm{X} 1 * \mathrm{X} 2+2.47 * \mathrm{X} 1 * \mathrm{X} 4+3.34 * \mathrm{X} 3 * \mathrm{X} 4-2.09 * \mathrm{X} 1 * \mathrm{X} 2 * \mathrm{X} 3+$ $1.92 * \mathrm{X} 1 * \mathrm{X} 2 * \mathrm{X} 4+3.71 * \mathrm{X} 1 * \mathrm{X} 3 * \mathrm{X} 4$ .. (1)

\section{For response drug entrapment efficiency (\%)}

$\mathrm{DEE}(\mathrm{Y} 1)=+72.96+12.96 * \mathrm{X} 1+4.45 * \mathrm{X} 2-$ $0.64 * \mathrm{X} 3+1.05 * \mathrm{X} 1 * \mathrm{X} 2+0.74 * \mathrm{X} 1 * \mathrm{X} 4+0.68 * \mathrm{X} 2 * \mathrm{X} 3 \quad-0.23 * \mathrm{X} 2 * \mathrm{X} 4 \quad+$ $0.25 * \mathrm{X} 3 * \mathrm{X} 4+1.60 * \mathrm{X} 1 * \mathrm{X} 2 * \mathrm{X} 4+0.51 * \mathrm{X} 1 * \mathrm{X} 3 * \mathrm{X} 4+0.82 * \mathrm{X} 1 * \mathrm{X} 2 * \mathrm{X} 3 * \mathrm{X} 4$ (2)

\section{Estimation of quantitative effects of factors}

A factor was considered to influence the response if the effects are significant $(\mathrm{p}<0.05)$. A positive value indicates a synergistic effect that favors optimization, while a negative sign represents an antagonistic effect or inverse effect of the factor on the selected response [13]. When we study the optimization of formulation for $100 \mathrm{mg}$ constant drug amount considering $70 \% \mathrm{CPR}$ at $8 \mathrm{~h}$ and $100 \%$ Drug Entrapment Efficiency it was observed that $200 \mathrm{mg}$ total polymer, $30 \%$ gelatin wrt total polymer and $6 \mathrm{~h}$ oxidation reaction time is the predicted optimized formula for around 91\% DEE and $72 \% \mathrm{CPR}$ at $8 \mathrm{~h}$. This prediction matches with the formulation No. F5. It is shown in an equation that response Y1 (CPR at $8 \mathrm{~h}$ ) was significantly influenced by the synergistic effect of total polymer concentration (A). For second response Y2 (percentage entrapment efficiency), the significant factors were identified as both the polymer and interactions of polymer and Xanthan gum dialdehyde.

\section{DSC analysis}

DSC thermogram of Xanthan dialdehyde cross-linked blank bead, drug-loaded bead and the drug metoprolol are displayed in fig.

Thermogram of the pure drug shows a sharp endothermic peak at $145{ }^{\circ} \mathrm{C}$ indicating its melting point. Drug formulation does not show any peak means that drug is in amorphous state in the formulation. 


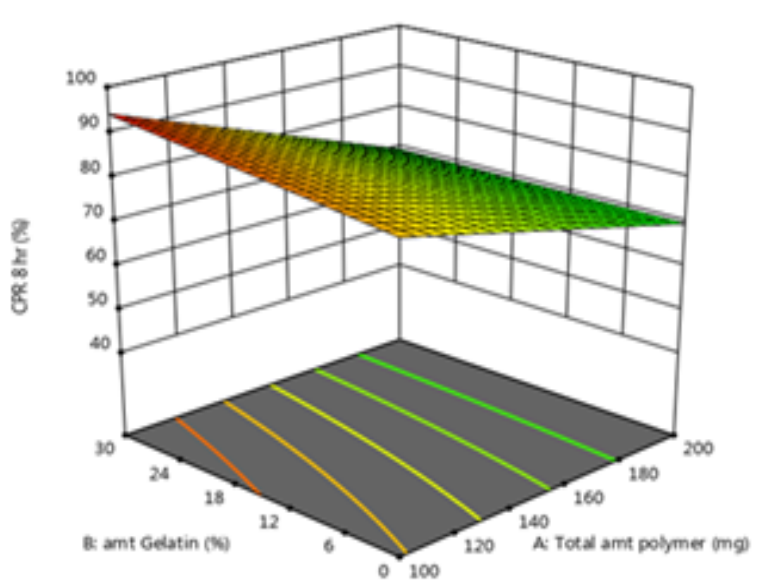

a. Response surface diagram of the effect on CPR at $8 \mathrm{hr}$ due to interaction of total polymer and gelatin amount

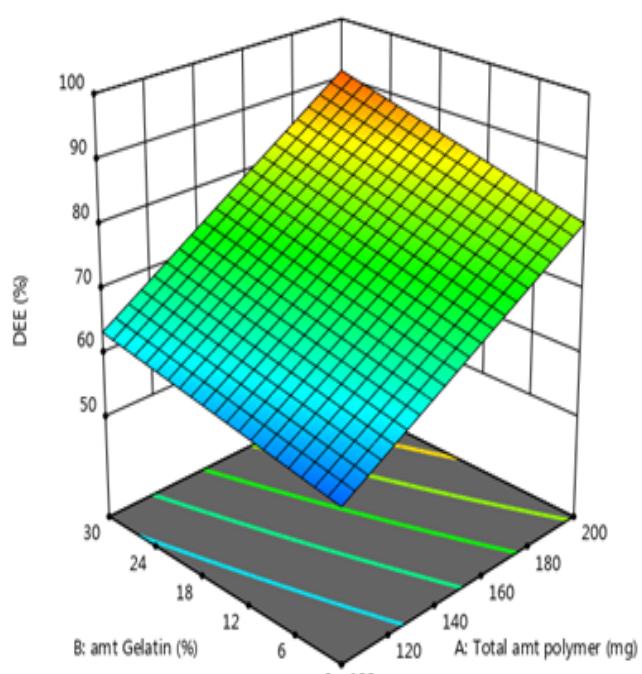

$\mathrm{b}$ : Response surface diagram $100 \mathrm{f}$ effect on DEE due to interaction total polymer and gelatin amount

Fig. 3: Response surface diagram for the effect total polymer amount and presence of gelatin on CPR at $8 \mathrm{~h}$ (a) and DEE(b)

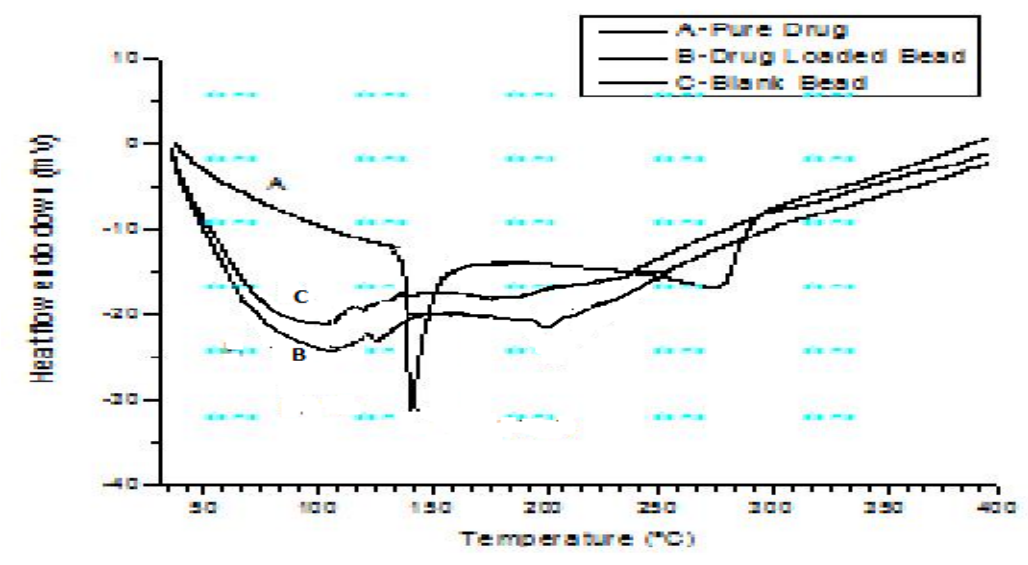

Fig. 4: DSC analysis of drug, drug loaded formulation and blank formulations

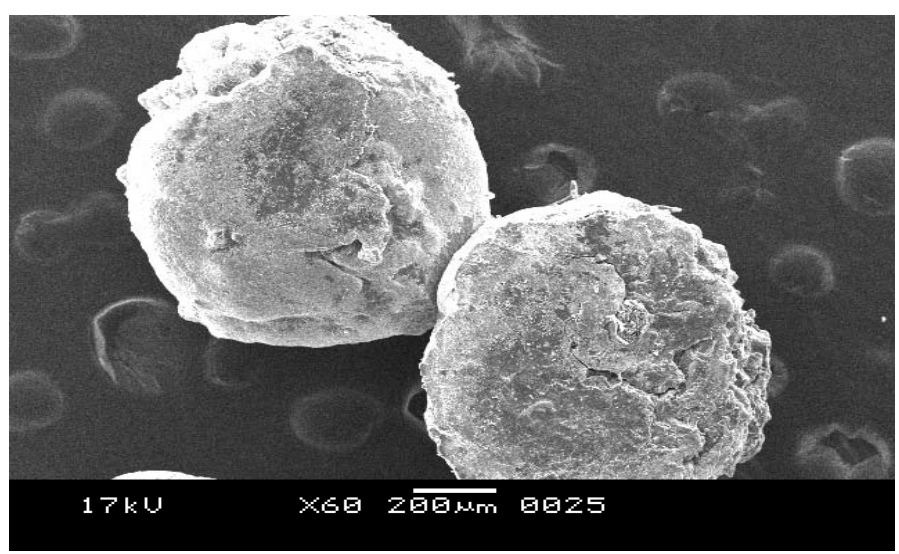

Fig. 5: SEM analysis of drug-loaded formulation

\section{SEM analysis}

SEM of microspheres was taken at high magnifications. The formulations were all hemispherical. The surfaces were not very smooth and present in a compact form and drug crystal are not visible in the surface.

\section{Swelling study}

Here swelling study is done in two different swelling medium i.e. 0.1 (N) $\mathrm{HCl}$ of $\mathrm{pH} 1.2$ and phosphate buffer solution of $\mathrm{pH}$ 6.8. The data of swelling ratio in $\mathrm{pH} 1.2$ and $\mathrm{pH} 6.8$ were presented in table. The data show that the microspheres have a more swelling ratio in $\mathrm{pH} 1.2$ from 
79.90\%-51.37\% than in $\mathrm{pH} 6.8$ from $32.94 \%-22.10 \%$. The amount of polymer concentration has a great effect on swelling ratio as well as in drug entrapment and release rates of drug. As the polymer concentration is increased swelling ratio is also increased due to more water entrapment. The presence of gelatin also increases the swelling ratio. The oxidation reaction time for formation of cross-linker has also affected the swelling ratio. When XDA2 in the matrice increases, the percent equilibrium water uptake significantly decreases. This is mainly due to increased crosslink density and decreased pore volume of the polymeric network with increasing aldehyde group in the oxidized xanthan in the matrix. But the presence of gelatin significantly increases the swelling ratio amongst all the factors.

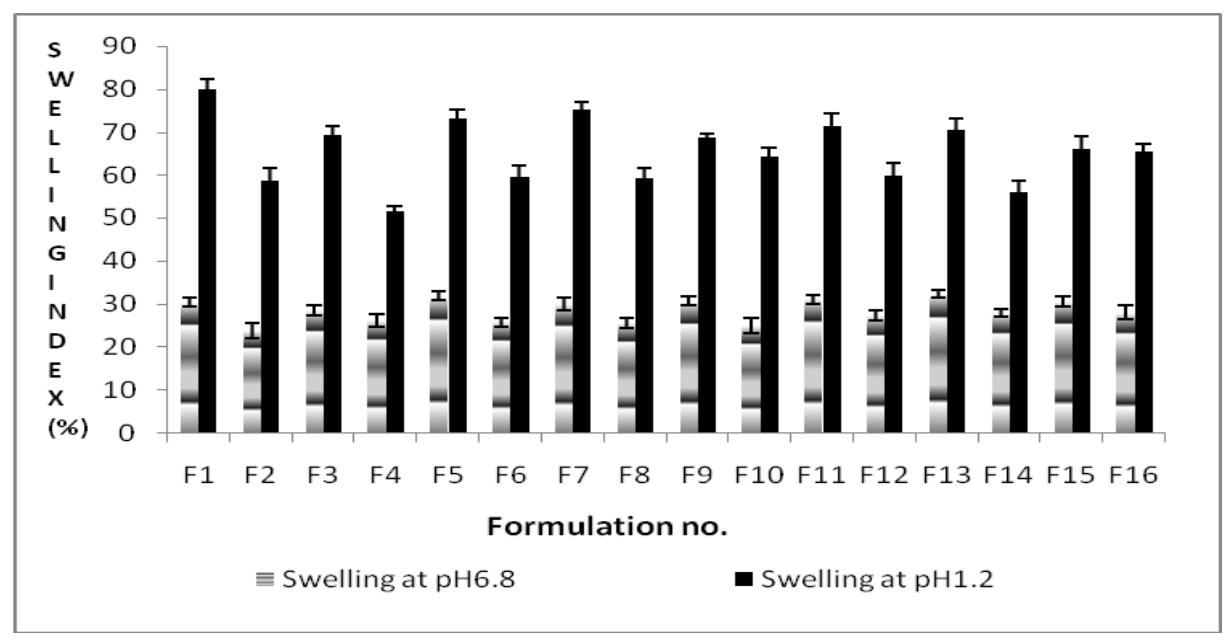

Fig. 6: Comparison of swelling ratio at $4 \mathrm{~h}$ of all the formulations at different $\mathrm{pH}$, all values are expressed as mean $\pm \mathrm{SD}, \mathrm{n}=3$

\section{In vitro drug release study}

In vitro drug release study data show that an increase in polymer concentration and presence of gelatin produce positive impact but the oxidation reaction time has a negative effect on drug release. It is observed from the result that F3, F5. F7. F13 and F15 have CPR at 8h within 68 to $76 \%$. But among them F5 formulation matches both the requirements of DEE and CPR. In all the cases total polymer amount is maximum. That indicates total poly concentration plays major role for development of the formulation. F2, F6, F8 and F14 have shown more than $90 \%$ release at $8 \mathrm{~h}$. In all the cases total polymer amount is $100 \mathrm{mg}$. It may be due low retardation effect exerted by total polymer system.

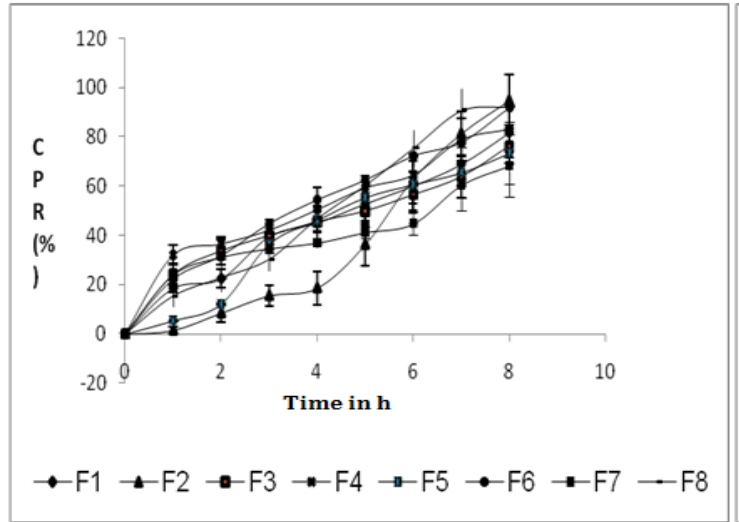

A)

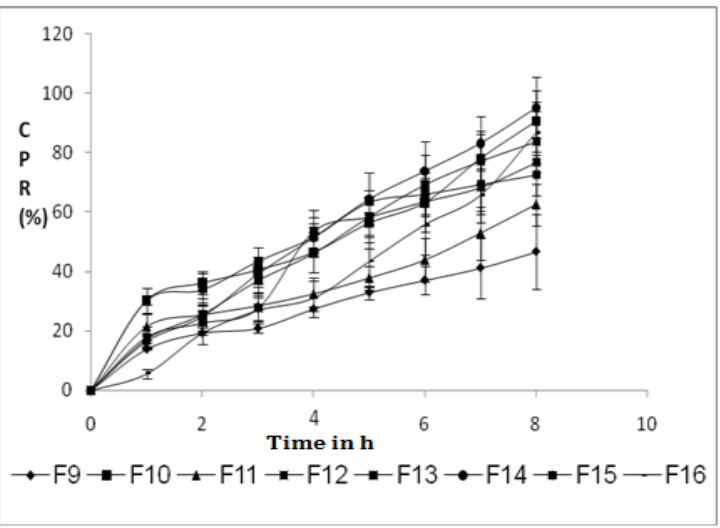

B)

Fig. 7: Comparison of In-vitro dissolution rate study of Formulation F1 to F8(A) and F9 to F16 (B) at pH 6.8 buffer, ${ }^{*} \mathrm{All}$ results were plotted as mean $\pm S D, n=3$

\section{Determination of the release kinetics}

Release kinetics of micro-particles were evaluated with various models using KinetDS3.0 software and it was observed that all the formulations followed the emperical model that follow dissolution based mechanism such as Zero-order, Korsmeyer-Peppas model, Weibull equation and Hill equation. By using Korsmeyer and Peppas equation, the $n$ values were obtained more than 1 (table 3 ) for all formulations. These values are characteristic of super case-II transport, suggesting that more than one mechanism may be involved in release kinetics. The mechanism of drug release can be described by the phenomenon that involves the disentanglement and erosion of the polymer. The release process involves the penetration of water into dry matrix followed by hydration and swelling of the polymer, and diffusion of the drug dissolved in the matrix [14]. For all the formulations, the contribution of polymer relaxation occurs throughout the entire dissolution time period. This was also apparent from the $\mathrm{n}$ values obtained (table 3 ), which approaches super case-II [15\} transport. In general, the relaxation contribution was higher for the formulations with higher $\mathrm{n}$ values. 
Table 3: Kinetic model analysis of the release of metoprolol from microparticles

\begin{tabular}{|c|c|c|c|c|c|c|}
\hline \multirow[t]{2}{*}{ Formulation } & \multirow{2}{*}{$\begin{array}{l}\text { Zero-order } \\
\mathbf{r}\end{array}$} & \multicolumn{2}{|c|}{ Korsmeyer pappas } & \multirow{2}{*}{$\begin{array}{l}\text { Weibull } \\
\mathbf{r}\end{array}$} & \multirow[t]{2}{*}{ DE (\%) } & \multirow[t]{2}{*}{ MDT(h) } \\
\hline & & $\mathbf{r}$ & n & & & \\
\hline F1 & 0.98 & 0.99 & 1.098 & 0.99 & 43.58 & 3.74 \\
\hline F2 & 0.91 & 0.99 & 1.08 & 0.99 & 34.01 & 5.12 \\
\hline F3 & 0.94 & 0.99 & 1.09 & 0.99 & 43.96 & 3.39 \\
\hline $\mathrm{F} 4$ & 0.94 & 0.99 & 1.10 & 0.99 & 50.74 & 3.11 \\
\hline F5 & 0.96 & 0.99 & 1.09 & 0.99 & 39.84 & 3.66 \\
\hline F6 & 0.978 & 0.99 & 1.10 & 0.99 & 51.5 & 3.66 \\
\hline F7 & 0.91 & 0.99 & 1.09 & 0.99 & 38.39 & 3.5 \\
\hline F8 & 0.99 & 0.99 & 1.10 & 0.99 & 48.5 & 3.8 \\
\hline F9 & 0.96 & 0.99 & 1.07 & 0.99 & 26.99 & 3.36 \\
\hline F10 & 0.97 & 0.99 & 1.10 & 0.99 & 49.57 & 3.6 \\
\hline F11 & 0.95 & 0.99 & 1.08 & 0.99 & 34.11 & 3.6 \\
\hline F12 & 0.99 & 0.99 & 1.10 & 0.99 & 46.59 & 3.5 \\
\hline F13 & 0.96 & 0.99 & 1.09 & 0.99 & 43.7 & 3.4 \\
\hline F14 & 0.95 & 0.98 & 1.08 & 0.99 & 34.1 & 5.14 \\
\hline F15 & 0.96 & 0.99 & 1.09 & 0.99 & 42.56 & 3.41 \\
\hline F16 & 0.94 & 0.99 & 1.10 & 0.99 & 48.12 & 3.71 \\
\hline
\end{tabular}

\section{CONCLUSION}

In this study, xanthan gum was successfully oxidized to form dialdehyde. Microparticles of Chitosan-gelatin polymer combined matrices containing metoprolol succinate were successfully prepared using xanthan gum dialdehyde as crosslinker. The drug release from these polymer systems was studied and it was observed that total polymer amount and chitosan to gelatin ratio influenced the release rate maximum. The release kinetics followed the super case II model.

\section{ACKNOWLEDGMENT}

The authors are grateful to The Chairman, Gupta College of Technological Sciences who have supported this research.

\section{AUTHORS CONTRIBUTIONS}

All the author have contributed equally

\section{CONFLICT OF INTERESTS}

Declared none

\section{REFERENCES}

1. Al-Nemrawi NK, Alsharif SSM, Dave RH. Preparation of chitosantpp nanoparticles: the influence of chitosan polymeric properties and formulation variables. Int J Appl Pharm 2018;10:60-5.

2. Lee E, Park SJ, Lee JH. P-049-preparation of chitosan-TPP nanoparticles and their physical and biological properties. Asian J Pharm Sci 2016;11:166-7.

3. Bigi A, Cojazzi G, Panzavolta S, Roveri N, Rubini K. Stabilization of gelatin films by crosslinking with genipin. Biomaterials 2002;23:4827-32.

4. Jameela SR, Jayakrishnan A. Glutaraldehyde crosslinked chitosan as a long-acting biodegradable drug delivery vehicle: studies on the in vitro release of mitoxantrone and in vivo degradation of microspheres in rat muscle. Biomaterials 1995;16:769-75.
5. Draye JP, Delaey B, Voorde AVD, Bulcke AVD, Bogdanov B, Schacht F. In vitro release characteristics of bioactive molecules from dextran dialdehyde cross-linked gelatin hydrogel films. Biomaterials 1998;19:99-107.

6. Guo J, Li X, Mu C, Zhang H, Qin P, Li D. Freezing-thawing effects on the properties of dialdehyde carboxymethyl cellulose crosslinked gelatin-MMT composite films. Food Hydrocolloids 2013;33:273-9.

7. Ojha S, Kumar B. Formulation and optimization of chitosan nanoparticles of dimethyl fumarate using box-behnken design. Int J Appl Pharm 2016;8:10-7.

8. Angadi SC, Manjeshwar LS, Aminabhavi TM. Interpenetrating polymer network blend microspheres of chitosan and hydroxyethyl cellulose for controlled release of isoniazid. Int J Biol Macromol 2010;47:171-9.

9. Banerjee S, Ray S, Maiti S, Sen KK, Bhattacharyya UK, Kaity S, et al. Interpenetrating polymer network (IPN): a novel biomaterial. Int J Appl Pharm 2010;2:28-34.

10. Kim UJ, Kuga S, Wada M, Okano T, Kondo T. Periodate oxidation of crystalline cellulose. Biomacromolecules 2000;1:488-92.

11. Guo J, Ge L, Li X, Mu C, Li D. Periodate oxidation of xanthan gum and its crosslinking effects on gelatin-based edible films. Food Hydrocolloids 2014;39:243-50.

12. Kovvasu SP, Chowdary KPR. Formulation development and In vivo evaluation of pioglitazone Inclusion complexes: a factorial study. Int J Appl Pharm 2018;10:49-55.

13. Kothiya OM, Bhavana A, Patel BA, Patel KN, Madhabhai M Patel. Formulation and characterization of sustained release matrix tablets of ivabradine using $3^{2}$ full factorial design. Int J Appl Pharm 2018;10:59-66.

14. Jaya S, Divya S. Formulation and in vitro evaluation of matrix tablets of metoclopramide hydrochloride. Int J Appl Pharm 2019;11:25-30.

15. Deshpande AH, Despande WD. Design and evaluation of foodgrade wax matrix sustained-release mini-tablets of montelukast sodium. Asian J Pharm Clin Res 2017;10:317-21. 